\title{
The strong connection between marine engineering and marine environmental education within a marine cluster
}

\author{
Mirela Iuliana Sundri ${ }^{1, *}$ and Feiza Memet $^{1}$ \\ ${ }^{1}$ Constanta Maritime University, Faculty of Naval Electromechanics, 104 Mircea cel Batran Street, \\ 900663 Constanta, Romania
}

\begin{abstract}
Marine Environmental Education (MEE) is a vital activity, since the marine environment is impacted by industrial and technologies involved in this sector. MEE is in strong connection with marine engineering. The players from this industry have to comply with environmental protection protocols and conventions. A marine cluster is a good way of approaching issues specific to the exploitation of resources of the sea. In the present, a particularity of marine pollution is that in enclosed seas (such as Black Sea is) and on coastal areas, the pollution is higher than in the open ocean. In order to fight with this reality, it is also vital to increase the public environmental awareness throughout specific education, not only to train specialists in this respect. This paper is providing the pylons on which MEE relies. From this paper will succeed how the objectives of MEE (awareness, knowledge, attitude, skills, participation) and its specific actions (environmental education and training, involvement, bringing people together) are supported by a marine cluster. The most important result of this study can be stated as: processes developed within MEE will enforce the involvement of specialists in solving marine pollution issues and will rise the environmental consciousness of communities, in a framework provided by a cluster oriented towards MEE.
\end{abstract}

\section{Introduction}

A cluster is a union, an association between different entities, geographically concentrated and interrelated in a certain social field of activity, seeking to achieve a common goal [1]. According to Krugman, cluster members establish, in time, a social bond able to act in the manner of working in a positive direction [2].

Clusters are frequently used as tools of measurement of the economic specialization of a country or of a region/cross-borders region, since the competitiveness of the cluster is affected by the activity of the member entities and also by the relationship between them [3].

\footnotetext{
*Corresponding author: iuliana.sundri@.cmu-edu.eu
} 
Entities entering in a cluster are aware of the main advantages of this union, as seen in figure 1 [4].

Maritime transport is based on two pylons: maritime shipping and port activities; its performances depend on sustainability-which is achieved throughout overcoming barriers to innovation [5].

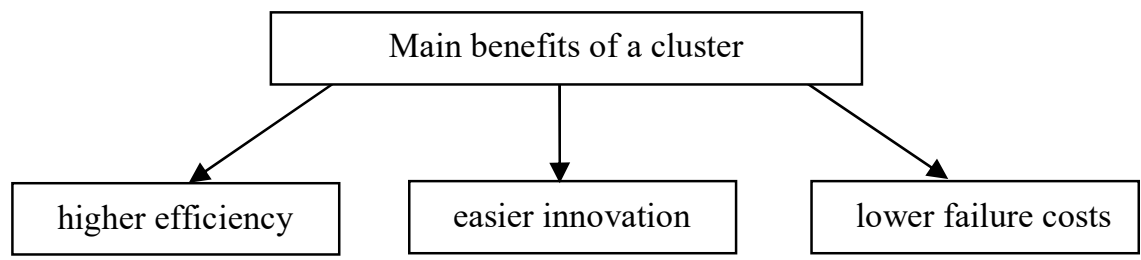

Fig. 1. Main advantages offered by a cluster to its members

It is expected that a maritime cluster will be a mean to achieve a better articulation and will strengthen the usage of synergies, while it will facilitate the construction of a sustainable and integrated perspective of the sea, of its resources and wide range of related activities (see figure 2) [6], [7].

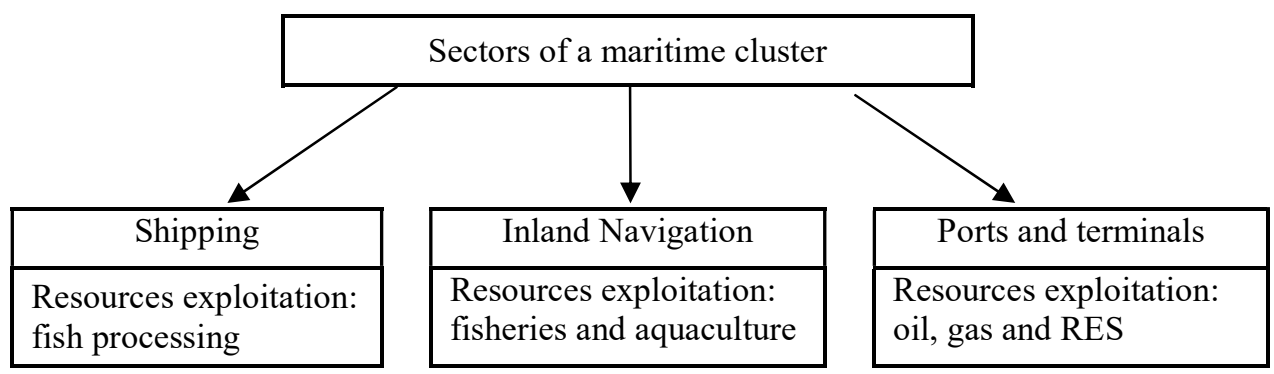

Fig. 2. Layout of sectors of a maritime cluster

In Europe, marine clusters are seen as important entities due to the fallowing realities [8]:

- $\quad$ approximately $40 \%$ of the world fleet belongs to our continent;

- $\quad$ Europe is in the top of coastal vacation destination list;

- $\quad$ European yacht builders lead this market, European dredging and RES companies as well;

- European maritime research, inland shipping and fishing are in the head of international hierarchy.

There are several marine clusters all over the world. Their objectives are gathering actors in order to reach desiderates such as: sustainable growth in the region, competitive maritime sector, integration of regional maritime activity in the international one. The relevance and the objective of this study consist in the integration of Marine Environmental Education activity in the classic tasks of a cluster, established in the Black Sea region, in order to form a new mentality of the people from this region and to strengthen specialist's cooperation, for solving actual pollution issues, but also to prevent future ones. In this respect, in the following we will describe the pylons on which MEE relies, and the objectives of MEE. For a successful MEE activity in the Black Sea Region, we provide the actions of MEE which must be developed within the Black Sea Marine Cluster. 


\section{Sources of marine pollution}

The majority of coastal areas are affected by pollution, outputs of this negative aspect being found in commercial coastal and marine fisheries. This is why it is important to have in view the following brief presentation of the significant pollutants, when trying to fight against [9], [10], [11], [12]:

- agricultural activities: represent approximately 50\% of water pollution sources in throughout agricultural input products, such as nutrients; regarding aquaculture, it is stated the need of control the effluents, since pesticides are known to be an aggressive agent acting on the aquatic ecosystem;

- domestic and industrial activities: domestic and industrial sewage are met in water courses, even in the ocean, resulting a diminish in the oxygen level fact that is found in a lower quality of river, sea and ocean waters;

- oils: oil from shipping activities is the major marine pollutant; this pollutant may end in seas and oceans by different ways (spills, daily activities, runoffs or clumping) which causes damage on marine organisms, aquatic plants and birds;

- heavy metals and trade elements: these pollutants (outputs of various industries) end in the seas or oceans through atmospheric or onshore effluent sources; they cause disturbs in the metabolic process and loss of intercellular constituents;

- $\quad$ organic compounds: are dangerous because of their high toxicity and long life in the surroundings and in the biological systems;

- plastics: this is a banned pollutant because they affect the marine environment through entangling life and damaging coral reefs;

- $\quad$ suspended particulate matter: cause difference in levels, bound in restrictions of sunlight penetration; as a result, it is registered an obstacle in the growth of plants (such as algae);

- eutrophication and algal bloom: have a negative impact on aquatic animals and, also, in time, it will be found an important layer of dead and decomposing organism on the bottom; moreover, they are totally unaesthetic;

- biological pollution: are issues of concern raised by delivery, movement and existence processes specific to non-indigenous or invasive species in waters and estuarine areas; this type of pollutants have the capacity of diminish the fitness for survival of level of biological organization.

Strictly regarding the Black Sea (which is an important sea among European Seas, since it supports economics of six countries) anthropogenic activities, eutrophication, natural variability and climatic change are topics of interest for specialists. Tendencies in the development of coastal communities lead to uncontrolled industrial and domestic wastes. In addition, it should be also considered the fact that Black Sea is of semi closed type, this is why aeration of deep water layers through lateral flows is not fast. Moreover, strong density stratification inhibits vertical mixing.

Having in view the various pollution issues specific to the Black Sea, the prosperity of the communities and the natural diversity of species, measures to increase environmental awareness have to be taken. In this respect, this paper is bringing into attention the need of a Black Sea Marine Cluster set up, dealing with Marine Environmental Education (MEE). We strongly affirm that this cluster can be used as an effective tool of educating communities and stimulating specialists through, aspect which will be discussed in the following. 


\section{Marine Environmental Education in the task of Black Sea Marine Cluster (BSMC)}

Our opinion is that the Black Sea Marine Cluster oriented towards MEE should be developed as a geographical concentration of different bodies, from countries which border Black Sea, willing to cooperate within a busiest model that is able to bring development, innovation, competitiveness and growth in the region. These countries are: Romania, Bulgaria, Ukraine, Russia, Georgia, and Turkey. The members of BSMC should come from different fields, so that they have to be: universities, high schools, research institutes, companies, NGOs, public authorities.

Marine Environmental Education (MEE) is the link between marine engineering and marine environment. MEE is a tool at the hand of cluster members that enables involvement and learning by persons of different ages in order to review and change perspective on the preservation of clean seas and coastal areas.

We found the pylons on which MEE rely. They are given in figure 3 and we describe them below:

1. fundamental environmental concept and elements: should be introduced in existing disciplines delivered to students in high school and universities;

2. new environmental chapters and modules: included in existing courses in order to catch the detail of the environmental problem;

3. new extra curricula programs and courses: delivered by a different institution, which end with a certification, in order to upgrade existing knowledge and understanding;

4. more scientific papers and research studies on projects: must be released in order to indicate how specialists are facing the challenge;

5. higher priority on trainers training: in order to make them spread updated information and to enforce of tertiary education and research capabilities;

6. intensive specific research on MEE policies and practices: in order to get good outputs through MEE;

7. intensive know-how exchange between users of marine environmental skills: in order to take advantage of partners' achievements in the field;

8. attention on adult and community marine environmental education through formal education (form of education developed in schools and universities) and non-formal education (form of education based on a strategy which do not imply student attendance): in order to increase the global environment literacy standards.

9.

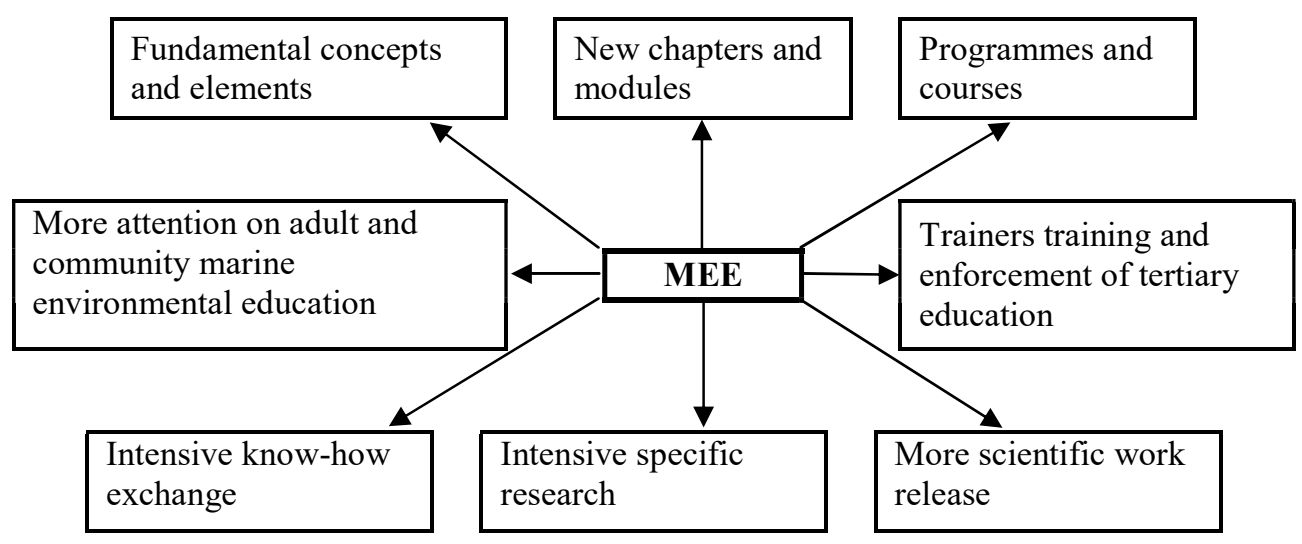

Fig. 3. MEE pylons 
The aim of MEE is to make people aware of the importance of the marine and coastal environment and make them act in a manner which is in harmony with the marine environment, by gaining knowledge and skills specific to a sustainable interaction with the natural world.

The objectives of MEE, identified in this paper are as follows:

I. awareness - MEE has to make people awake about the problems related to the environmental debate;

II. knowledge - MEE has to contribute to the knowledge gaining (by individuals and social groups) related to their environment;

III. attitude - MEE has to determine individuals and social groups to accept modifications of behaviour in order to reach cleaner water and coasts

IV. skills - MEE has to make people have necessary skills needed for the identification of the marine environmental problem;

$\mathrm{V}$. participation - MEE has to make people to feel and act responsible so that marine environmental issues are solved in the region.

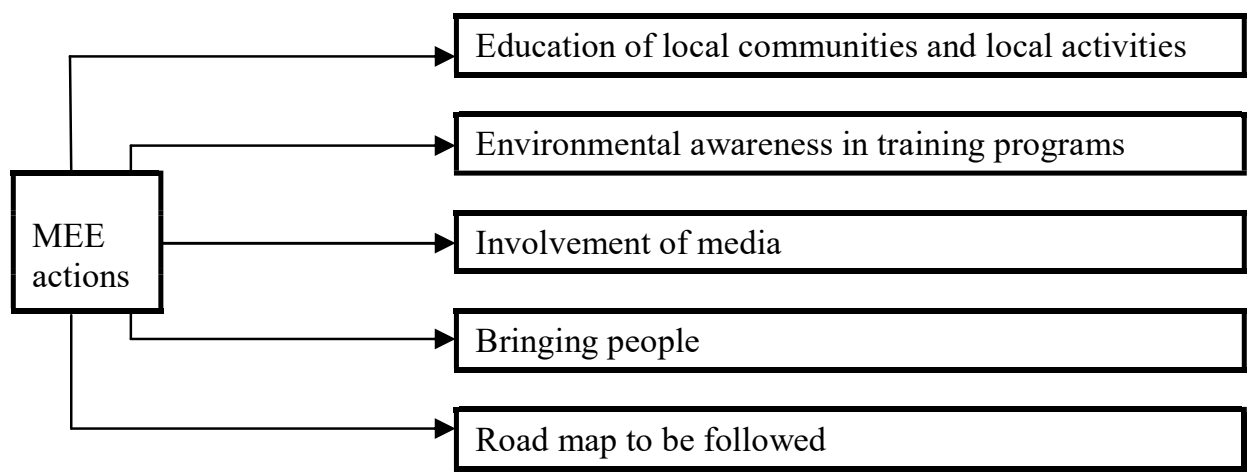

Fig. 4. MEE actions

We provide below the specific MEE actions (see figure 4):

a) education of local communities and local representatives: emblematic figures of the communities may decisively influence the behaviour of persons, especially in rural zones; first, an assumed attitude of this individuals towards clean seas and coastal areas has to be noticed;

b) environmental awareness in training programs: is a feature developed by training programs held in institutions, for working adults, in order to upgrade their knowledge, but also, marine environmental concepts might be included in student curricula;

c) involvement of media: in its different forms (TV, radio, newspaper) is of huge importance since media reach any individual of a community;

d) bringing people together: it is a vital action - BSMC has the capacity of bringing together specialists, future specialists, representatives of governmental organization and journalists, in order to effectively work within projects or networks aiming a cleaner sea and coasts;

e) road map to be followed: it has the following five objectives:

- management of climate change - it is about communication with enterprises, finding challenges needing further assessment and decision support, inclusion of climate change adaptation within each entity's activities;

- $\quad$ protection of basic resources against potential impacts related to climate change - it is about identification of potential impacts of climate change and risks determination in order to identify specific measures; 
- $\quad$ ensure the communities against more often natural events and disasters - it is about finding the proper way of fighting against physical and economical losses; it requires adequate policies and standards, funding for specific researches and work force;

- $\quad$ contribution to safety, stability, security and environmental protection - it is about support actions able to serve as foundation on which safety, stability and security in the region are built;

- $\quad$ publicity - it is about the organization of press conferences and radio campaigns throughout banners, booklets and leaflets within an awareness raising campaign; are aimed valuable assets and workforce development opportunities, in order to reach the mentality of an important number of people living in the region.

\section{Conclusions}

The future of the Black Sea strongly depends on actions taken by people.

Marine and coastal pollution in the region is now subject of concern. Specialists and local communities have to change radically their mentality and life. But, as stated in this paper, this is possible throughout environmental awareness and education intensification.

We highlighted the fact that the BSMC might coordinate the actions needed to be taken in order to make communities and specialists to work together in order to establish a harmony with the sea.

This desiderate will be reached through Marine Environmental Education (MEE), managed by this cluster, as tool at the hand of the cluster members: education and research institutions, companies, NGOs and public administration entities.

The objectives and the actions of MEE, given in this paper, will enforce the involvement of specialists in solving marine pollution issues and will rise the environmental consciousness of communities, in a friendly framework provided by the cluster.

\section{References}

1. M.R. Funaric, K.P. Galic, IJHASS, 5 (5) 650 (2011)

2. P.R. Krugman, Geography and Trade Leuven, 156 (1991)

3. M.H. Nijam P.W. de Langen, ERSA 2003 Congress, 23 (2003)

4. J.P. Rodrigue, International Transport Forum 2010, Transport and Innovation: Unleashing the Potential 22 pp. (2010)

5. P. Ripatti, Creating a Marine Cluster. From Product Supply to System Solutions, 70, (2014)

6. P. Monteiro, T. de Noroha, P. Neto, Sustainability 5 (9), 4076 (2013)

7. S. Theodoropoulos, E. Tassopoulos, IJEBA, 2, 3, 3-14 (2014)

8. European Commission, https://ec.europa.eu/maritimeaffairs/sites/maritimeaffairs/files/docs/body/report_results _en.pdf, Accessed in March 2020

9. M.S. Islam, M. Tanaka, Marine Pollution Bulletin, 48, 624-649 (2004)

10. D. Xanthos D, T.R. Walker, Marine Pollution Bulletin, 118, 1-2, 17-26 (2017)

11. M. Vikas, G.S. Dwarakish, Aquatic Procedia 4, 3, 381-388 (2015)

12. L. Bat, A. Oztekin, F. Şahim, E. Arici, U. Ozsandikei, MedFAR 1 (2), 66-86 (2018) 